\title{
Making a Telescope Mirror
}

\section{J.M. Becker}

20 rue du Petit Chinois, F-25200 Montbélliard, France

A video presentation of all stages in the manufacture and testing of a $200-\mathrm{mm}$ mirror. [The video cassette may be obtained from ASTAM, Viry, 39360 Vaux-lesSainte Claude, France].

\section{Searching for Comets}

\section{Ben Mayer}

1940 Cotner Ave., Los Angeles, CA 90025, U.S.A.

Methods of searching for comets, novae and other events using projection and video blink methods, and simple orientation aids were described. The methods are covered in the following references:

1. Liller, W., Mayer, B.: The Cambridge Astronomy Guide, Cambridge University Press, 1985

2. Mayer, B.: International Halley Seminar, Alden Biessen, Belgium, 1986 Oct.25

3. Mayer, B.: 20th ESLAB Symposium, "Exploration of Halley's Comet", Heidelberg, 1986 Oct.27-31

4. Mayer, B.: Mercury, (Journal of the Astronomical Society of the Pacific), 1987 July/August 